\title{
Are measurements of height made by health visitors sufficiently accurate for routine screening of growth?
}

\author{
M L Ahmed, P L Yudkin, J A Macfarlane, K McPherson, D B Dunger
}

\begin{abstract}
To find out whether measurements of height made by health visitors are sufficiently accurate for use in routine screening of children we carried out an interobserver and intraobserver reliability study. Height measurements were made on a group of 10 children aged 3 years old and 10 aged 4.5 years old by two sets of four health visitors. They used a Microtoise or wall chart and the measurements were compared with those made by a trained auxologist with a Harpenden stadiometer. For a single assessment of height both pieces of equipment gave reasonably accurate results. In a child aged 3 years, with height measured on the Microtoise as $100 \mathrm{~cm}$, the true height could be expected-with $95 \%$ probability-to lie between $99.2 \mathrm{~cm}-101.8 \mathrm{~cm}$. At the age of 4.5 years, if the measurement was $110 \mathrm{~cm}$, the child's true height could be expected to lie between $108.9 \mathrm{~cm}$ and 111.9 $\mathrm{cm}$. The narrowest confidence interval for the growth rate from 3 to 4.5 years was achieved with the Microtoise, taking the mean of three measurements.

We conclude that measurements made by health visitors are sufficiently accurate for routine screening of height, and the use of such measurements for the calculation of height velocity could be improved by more structured training.
\end{abstract}

It is essential to detect children with short stature and abnormally slow growth as early as possible so that problems that are amenable to treatment, such as growth hormone insufficiency, can be treated. In a recent national review of the child health surveillance programme it was recommended that all children should be screened for growth at 3 and 4.5 years. ${ }^{1}$

The Oxford wall chart (devised by AynsleyGreen and Macfarlane) provides a simple approach to population screening for short stature that can be used by health workers with only simple basic training. ${ }^{2}$ Screening to detect young children whose height lies more than 2 SDs below the mean height for age, however, may not detect all of those with growth hormone insufficiency. ${ }^{3}$ Early detection of these children requires an accurate assessment of growth velocity as the stature of these children may not have fallen outside the normal range by the age of 4.5 years.

Effective screening should therefore include both the measurement of height and an estimate of growth velocity, the calculation of which is dependent on two measurements. The accuracy of these measurements is therefore critical if the rate of false positive and false negative results is to be minimised.

Any national growth screening programme will have to rely on a primary health care team with little training in measuring techniques. Measurements undertaken as part of research protocols are usually made on sophisticated and often expensive pieces of apparatus, whereas measuring equipment provided for screening of the general population has to be simple and cheap.

To find out if measurements made by health visitors are sufficiently accurate for routine screening we undertook a study to examine the precision and accuracy of measurements made by health visitors with two simple pieces of equipment. Children at the ages of 3 and 4.5 years were measured and the results compared with those obtained by a trained auxologist with the standard equipment of a growth clinic: the Harpenden stadiometer.

\section{Subjects and methods}

The studies were carried out in the Oxford district with the approval of the local ethics committee. Ten 3 year old children and 10 aged 4.5 years old were recruited at random from a day nursery in Banbury. Two separate sets of four health visitors (one set for each age group) were given a brief period of instruction in the use of the Oxford Growth Screening Wall Chart (Castlemead Publications) and the Microtoise (Child Growth Foundation). They were then asked to make three separate measurements of each child with each piece of equipment. The children were measured in random order so that no child was measured by the same health visitor on consecutive occasions, and no health visitor had reference to previous measurements. Measurements made by the health visitors were then compared with those made by a trained auxologist (MLA) on a portable Harpenden stadiometer.

For the purpose of this analysis the stadiometer reading was assumed to be the correct height of the child. The accuracy of a measurement using any other method was therefore represented by the difference between this measurement and the stadiometer reading. In the analysis all the calculations were carried out on these differences, or biases. To see if there was any advantage in measuring each child three times and taking the mean value the analysis was carried out twice, firstly with the first
Correspondence to: Dr Dunger.

Accepted 9 July 1990
John Radcliffe Hospital,

Oxford

P L Yudkin

J A Macfarlane 
measurement alone, and secondly with the mean of the three measurements.

To estimate the precision of the measurements (that is, the extent to which measurement biases differed from one another) an analysis of variance was carried out, assuming a random effects model. In this model both the observers and the children are considered as randomly chosen and thus as representing particular sources of variation. The total variance attached to a single measurement bias was taken as the sum of the variances due to observers, to children, and to random error (including any interaction between observers and children). ${ }^{4}$ No allowance was made in the analysis for the sampling error of the variance estimates themselves.

\section{Results}

The mean (SD) of the measurement biases for the 10 children by age and method of measurement are shown in table 1 . The negative mean values show the tendency of both methods to record a height that was lower than the true (stadiometer) value. The accuracy of different observers varied widely. For instance, with the 3 year old children using one reading on the Microtoise, the mean bias ranged from $-0 \cdot 10$ $\mathrm{cm}$ for the most accurate observer to $-1.01 \mathrm{~cm}$ for the least accurate. With the 4.5 year old children the corresponding range was from $-0.06 \mathrm{~cm}$ to $-1.17 \mathrm{~cm}$.

The results for the 4.5 year old children show that the mean of three readings was slightly more accurate (that is, the mean bias was smaller) than the first reading alone. This was true for both the Microtoise and the wall chart. The opposite tendency was seen for the 3 year old children.

Table 1 Mean (SD) of measurement biases (cm) using the pooled results from all four health visitors

\begin{tabular}{|c|c|c|c|}
\hline \multicolumn{2}{|l|}{ Microtoise } & \multicolumn{2}{|l|}{ Wall chant } \\
\hline 3 years & 4.5 years & 3 years & 4.5 years \\
\hline $\begin{array}{l}\text { One reading: } \\
-0.48(0.55) \\
\text { Three readings: }\end{array}$ & $-0.37(0.54)$ & $-0.27(0.56)$ & $-0.24(0.57)$ \\
\hline$-0.58(0.50)$ & $-0.22(0.36)$ & $-0.46(0.46)$ & $-0.07(0.43)$ \\
\hline
\end{tabular}

Results from the analysis of variance are shown in table 2 . The components of variance (the variance attributed to each factor) show that for the 3 year old children the total variance was similar for both methods, but for the 4.5 year olds the mean of three readings using the Microtoise had the smallest total variance. For 3 year olds the proportion of total variance attributed to the children (between $29 \%$ and $51 \%$ of the total) was similar to the proportion attributed to the observers. In contrast, with the 4.5 year old children the proportion of the total variance attributed to the children (between 3\% and $13 \%$ ) was much smaller than that attributed to the observers.

The best estimate of the true height of a child is given by the measured height, with allowance made for the bias attached to the method of measurement used. The expected bias is the pooled mean from table 1 . Assuming a normal distribution, $95 \%$ of all biases would be expected to lie within 1.96 SD of the mean (values given in table 2). So if a value of $100.00 \mathrm{~cm}$ were recorded for the 3 year old child using one reading on the Microtoise, the interval $(100.00+0.48(1.30)) \mathrm{cm}$ that is $99.2 \mathrm{~cm}$ to $101.8 \mathrm{~cm}$ ) would be expected-with $95 \%$ probability-to include the true height of the child. If, using the same method, the child's height at 4.5 years were recorded as $110.00 \mathrm{~cm}$, the $95 \%$ confidence interval for the true height would be $(110+0.37(1.52)) \mathrm{cm}$-that is, 108.9 to $111.9 \mathrm{~cm}$.

If the same children were measured on both occasions, the $95 \%$ confidence interval for the 18 month growth would be $7.9 \mathrm{~cm}$ to $11.9 \mathrm{~cm}$ $(10.00+(0.37-0.48)(2.00) \mathrm{cm})$-that is, a growth velocity ranging between $5 \cdot 3$ and $7 \cdot 9$ $\mathrm{cm} /$ year (table 3 and figure). The reported growth rate would be $10 \mathrm{~cm}$ in 18 months-that is, $6.7 \mathrm{~cm} /$ year.

Our results suggest that the most precise esimate of growth would be achieved using the Microtoise, and taking the mean of three measurements. For instance, with three readings on the Microtoise the band described above $(7 \cdot 9$ $\mathrm{cm}$ to $11.9 \mathrm{~cm}$ ) would be narrowed to between $8 \cdot 1 \mathrm{~cm}$ and $11 \cdot 2 \mathrm{~cm}$.

\section{Discussion}

The conceptual and practical problems raised

Table 2 Components of variance of measurement biases (cm)

\begin{tabular}{|c|c|c|c|c|c|c|}
\hline & Observers & Children & Error & $\begin{array}{l}\text { Total } \\
\text { variance }\end{array}$ & $1.96 S D$ & $\begin{array}{l}95 \% \text { Confidence } \\
\text { interval for bias }\end{array}$ \\
\hline $\begin{array}{l}\text { Microtoise } \\
\text { At } 3 \text { years of age } \\
\text { One reading: } \\
\text { Mean of three readings: }\end{array}$ & $\begin{array}{l}0 \cdot 14 \\
0 \cdot 10\end{array}$ & $\begin{array}{l}0 \cdot 13 \\
0 \cdot 18\end{array}$ & $\begin{array}{l}0.17 \\
0.07\end{array}$ & $\begin{array}{l}0.44 \\
0.35\end{array}$ & $\begin{array}{l}1 \cdot 30 \\
1 \cdot 16\end{array}$ & $\begin{array}{l}-1.78 \text { to } 0.82 \\
-1.74 \text { to } 0.58\end{array}$ \\
\hline $\begin{array}{l}\text { At } 4.5 \text { years of age } \\
\text { One reading: } \\
\text { Mean of three readings: }\end{array}$ & $\begin{array}{l}0.31 \\
0.17\end{array}$ & $\begin{array}{l}0.03 \\
0.01\end{array}$ & $\begin{array}{l}0 \cdot 27 \\
0 \cdot 12\end{array}$ & $\begin{array}{l}0.60 \\
0.30\end{array}$ & $\begin{array}{l}1.52 \\
1.08\end{array}$ & $\begin{array}{l}-1.89 \text { to } 1.15 \\
-1.30 \text { to } 0.86\end{array}$ \\
\hline $\begin{array}{l}\text { Wallchart } \\
\text { At } 3 \text { years of age } \\
\text { One reading: } \\
\text { Mean of three readings: }\end{array}$ & $\begin{array}{l}0 \cdot 18 \\
0.18\end{array}$ & $\begin{array}{l}0 \cdot 14 \\
0 \cdot 14\end{array}$ & $\begin{array}{l}0 \cdot 17 \\
0.07\end{array}$ & $\begin{array}{l}0.49 \\
0.39\end{array}$ & $\begin{array}{l}1 \cdot 37 \\
1 \cdot 22\end{array}$ & $\begin{array}{l}-1.64 \text { to } 1.10 \\
-1.68 \text { to } 0.76\end{array}$ \\
\hline $\begin{array}{l}\text { At } 4.5 \text { years of age } \\
\text { One reading: } \\
\text { Mean of three readings: }\end{array}$ & $\begin{array}{l}0.37 \\
0.48\end{array}$ & $\begin{array}{l}0.09 \\
0.07\end{array}$ & $\begin{array}{l}0 \cdot 24 \\
0 \cdot 12\end{array}$ & $\begin{array}{l}0 \cdot 70 \\
0.67\end{array}$ & $\begin{array}{l}1.64 \\
1.60\end{array}$ & $\begin{array}{l}-1.88 \text { to } 1.40 \\
-1.67 \text { to } 1.53\end{array}$ \\
\hline
\end{tabular}


Table 3 Variance of measurement biases (cm): growth from 3 to 4.5 years

\begin{tabular}{|c|c|c|c|}
\hline & $\begin{array}{l}\text { Total } \\
\text { variance }\end{array}$ & $1.96 S D$ & $\begin{array}{l}95 \% \text { Confidence } \\
\text { interval for bias }\end{array}$ \\
\hline \multirow{2}{*}{$\begin{array}{l}\text { Microtoise: } \\
\text { One reading } \\
\text { Mean of three } \\
\text { readings }\end{array}$} & 1.04 & $2 \cdot 00$ & -1.89 to $2 \cdot 11$ \\
\hline & 0.65 & $1 \cdot 58$ & -1.22 to 1.94 \\
\hline \multirow{2}{*}{$\begin{array}{l}\text { Wall chart: } \\
\text { One reading } \\
\text { Mean of three } \\
\text { readings }\end{array}$} & $1 \cdot 19$ & $2 \cdot 14$ & $-2 \cdot 11$ to $2 \cdot 17$ \\
\hline & 1.06 & $2 \cdot 02$ & -1.63 to 2.41 \\
\hline
\end{tabular}

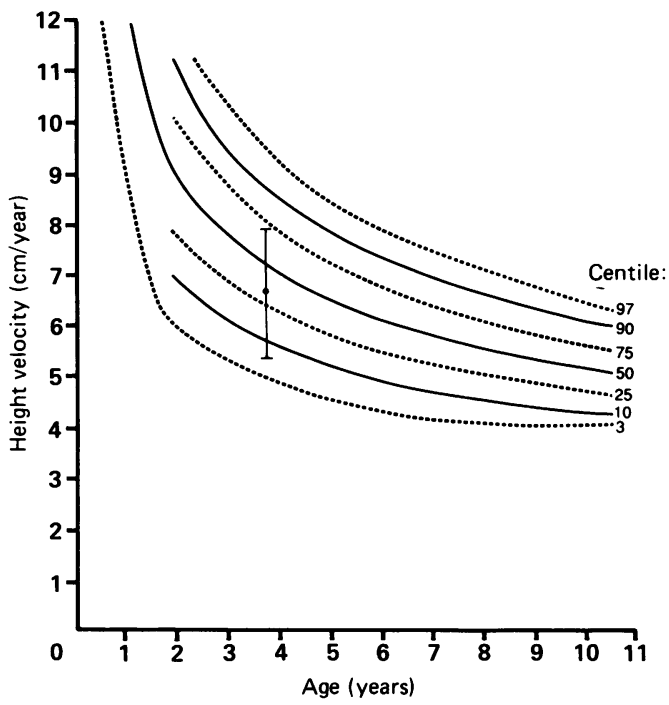

Height velocity standards of British boys. ${ }^{8}$ The vertical line at 3.75 years shows the $95 \%$ confidence interval of 5.3 to 7.9 cmlyear if the growth rate is $6.7 \mathrm{~cm} / \mathrm{year}$.

by errors of measurement are considerable. ${ }^{5}$ The results of our studies have important implications for current recommendations for screening of growth during childhood. They show that different observers, with basic training but little experience in measuring techniques, may vary in the accuracy of their recorded measurements. Interestingly, all the observers tended to record heights lower than those observed by the trained auxologist. Standing height shows diurnal variation, ${ }^{6}$ and the auxologist puts traction on the mastoid processes to decrease this. ${ }^{7}$ The auxologist may also be more successful at getting children to stand upright. Our data show that further practice in measuring techniques clearly has an effect on the accuracy of measurements. With both pieces of equipment the accuracy of measurement by the health visitors was greater when the mean of three results in the 4.5 year old children were analysed. A screening programme for growth would mean that health visitors had to make multiple measurements, which may lead to improved techniques. There was no improvement in accuracy, however, when the means of three results in the 3 year olds were analysed.

Not all of the variance in the observed measurement biases could be attributed to the observers. A substantial part of the variance observed in the younger age group could be attributed to the children, and this is not sur- prising when one contemplates the problems of ensuring an erect and relaxed posture in a 3 year old child. Accurate measurements in this age group are often doubted by the best trained auxologists, and if children of this age or younger are to be screened the possibility of measuring length rather than height must be considered. Whereas measurements of height in 3 year olds may be difficult, weight is easy to determine accurately. Weight measurements do not, however, provide us with sufficient information for the assessment of linear growth. If a child's weight increases with time we only know that he had become heavier-but whether this is due to excess fat, increased bone or muscle, or retention of body fluid as a result of some pathological condition, is unknown.

The Oxford wall chart provides a simple and reasonably accurate way of measuring a child's height. Our results suggest however, that a more precise measure of height was achieved with the Microtoise taking a mean of three measurements. The Microtoise has now been replaced by the Minimetre (also available from the Child Growth Foundation) and this piece of apparatus rather than the wall chart should therefore be recommended for routine screening.

The accuracy and precision of measurements made by primary health care workers will ultimately determine the value and efficacy of growth screening. For example, from a recorded height of $100.00 \mathrm{~cm}$ in a 3 year old child, one could predict with the Microtoise that the child's true height would lie between 99.2 and $101.8 \mathrm{~cm}$. This range is acceptable in screening for children with short stature but is it sufficiently accurate for the calculation of poor growth velocity? With the same methods, and by necessity with different observers, if the child's height at 4.5 years were recorded as 110 $\mathrm{cm}$, the true growth over this period would be expected to lie between 5.3 and $7.9 \mathrm{~cm} /$ year.

The reported growth rate in this child would be just above the 25th centile for velocity as reported by Tanner et al. ${ }^{89}$ The true growth rate, however, might lie anywhere between the sixth and the 72nd centile on the velocity charts. Clearly a definition of normal growth based on these centiles will produce a large number of false positive values on screening for short stature. These problems may be further compounded by short intervals between measurements, which do not allow for seasonal variations in growth, ${ }^{10}$ and the recently reported cyclical pattern of growth. ${ }^{11}$ If the recommended criterion of the 25 th centile for velocity as the cut off point for further investigation is adopted, errors in measurement will produce a large number of false positive results. ${ }^{3}$

Our results indicate that more training would improve the accuracy of measurements made by health visitors. Basic auxological training in both accurate measurement and interpretation of growth data must therefore be included in both health visitors' basic training and their 'inservice training'. Local training schemes for other primary health carers (including general practitioners) should also be considered before national growth screening can be undertaken. 
We would recommended the validation of screening programmes within selected health districts with understanding of the problems of measurement and the interpretation of data before national screening is carried out.

We thank Mrs D Carrington for organising the sessions with the health visitors and the day nursery. To Mrs Cape Horn (head of the nursery), her helpers, the health visitors, and the children go our thanks for their kind cooperation. Helpful comments from Professor MJR Healy and Dr I Vlachonikolis are warmly acknowledged. Support for the ongoing district growth screening is from Eli Lilly and Co; the portable Harpenden stadiometer was provided by the Child Growth Foundation.

1 Hall D, ed. Health for all children: a surveillance programme. Oxford: Oxford University Press, 1989.

2 Aynsley-Green A, Macfarlane JA. Method for the earlier recognition of abnormal stature. Arch Dis Child 1983;58 535-7.

3 Brook CGD, Hindmarsh PC, Healy MJR. A better way to detect growth failure. $\mathrm{Br}$ Med $\mathcal{f}$ 1986;293:1186.
4 Snedecor GW, Cochran WG. Statistical methods. 7th Ed. Ames, Iowa: Iowa State University Press, 1967:364-8. 5 Healy MJR. Measuring measuring errors. Stat Med 1989;8 893-906.

6 Whitehouse RH, Tanner JM, Healy MJR. Diurnal variation in stature and sitting height in 12-14 year old boys. Ann Hum Biol 1974;1:103-6.

7 Cameron N. The measurement of human growth. London: Croom Helm, 1984.

8 Tanner JM, Whitehouse RH, Takaishi M. Standards fror birth to maturity for height, weight, height velocity and weight velocity in British children 1965. Part I. Arch Dis Child 1966;41:454-71.

9 Tanner JM, Whitehouse RH, Takaishi M. Standards from birth to maturity for height, weight, height velocity and weight velocity in British children 1965. Part II. Arch Dis weight velocity in British

10 Marshall WA. Evaluation of growth rate in height over periods of less than one year. Arch Dis Child 1971;46: periods

11 Butler GE, McKie M, Ratcliffe SG. An analysis of the phases of mid-childhood growth by synchronization of growth spurts. In: Tanner JM, ed. Auxology 88.Perspectives in the science of growth and development. Proceedings of the 5th International Congress of Auxology. London: SmithGordon. 1988:77-84. 